\title{
Articles
}

\section{Factors Affecting the Magnitude of the Metal-Insulator Transition Temperature in $\mathrm{AMo}_{4} \mathrm{O}_{6}(\mathrm{~A}=\mathrm{K}, \mathrm{Sn})$}

\author{
Dongwoon Jung, ${ }^{*}$ Kwangsik Choi, and Sungjin Kim ${ }^{i, *}$ \\ Department of Chemistry and Institute of Basic Natural Science, Wonkwang University. Iksan. Jeonbuk 570-749. Korea \\ "Department of Chemistry, twha Linersity. Seoul 120-750, Korea \\ Received Jamany 30,2004
}

\begin{abstract}
A low-dimensional metal frequently exhibits a metal-insulator transition through a charge-density-wave (CDW) or a spin-densily-wave (SDW) which accompany it's structural changes. The transition temperature is thought to be determined by the amount of energy produced during the transition process and the softness of the original struclure. $\mathrm{AMO}_{1} \mathrm{O}_{6}(\mathrm{~A}-\mathrm{K}, \mathrm{Sn})$ are known to be quasi-one dimensional metals which exhibit metalinsulator transitions. The difference of the transition temperatures between $\mathrm{KMO}_{4} \mathrm{O}_{6}$ and $\mathrm{SnMo}_{1} \mathrm{O}_{6}(\mathrm{~A}-\mathrm{K}, \mathrm{Sn})$ is examined by investigating their electronic and structural properties. Fermi surface nesting area and the latlice softness are the governing factors to detemine the metal-insulator transition temperature in $\mathrm{AMO}_{1} \mathrm{O}_{6}$ compounds.
\end{abstract}

Key Words : Molybdenum oxide, Charge density wave, Electronic structure

\section{Introduction}

During the last decade, the metal-metal bonded ternery molybdenum oxide systems $\mathrm{KMo}_{4} \mathrm{O}_{b}{ }^{1}$ and $\mathrm{SnMo}_{4} \mathrm{O}_{6},{ }^{2}$ were successfully synthesized and characterized. These compounds are structurally similar in that they are low-valent molybdenum oxides containing $\mathrm{Mo}_{6} \mathrm{O}_{12}$ type octahedral clusters condensed by sharing trans-edges to form in linite chains, but are different in that either $\mathrm{K}$ or $\mathrm{Sn}^{21}$ cation is tilled in a square channel which is construcled by lour adjacent perpendicularly bridged chains. Since all chains are extended along the crystallographic c-direction, $\mathrm{AMo}_{4} \mathrm{O}_{6}(\Lambda-\mathrm{K}$, Sn) compounds are supposed to show one-dimensional (1D) electronic property. "On the basis of the assumption that the unique role of the cations are electron donors, the electronic structures of the electron withdrawing part (i.e., $\mathrm{Mo}_{4} \mathrm{O}_{6}{ }^{\prime}$ ) should be dillerent depending upon the charge of a cation.

Low dimensional metals often possess electronic instabilities toward a metal-insulator transition, which occur when the Fermi surface of their partially lilled bands are nested. ${ }^{4.5}$ In general, the Femi surface of a onc-dimensional metal is well nested, the 1D metal frequently shows a metal-insulator 1ransition. The metal-insulator transition can occur either at lower temperature or at higher temperature depending upon the latice softness and the amount of energy gain during the transition process which is related to the nested arca. It is necessary, therefore, to investigate structural and clectronic properties of low-dimensional metals in order 10 understand their different transition temperatures. In the present work. we report the factors affecting the magnitude of the metalinsulator transition temperature in $\Lambda \mathrm{Mo}_{4} \mathrm{O}_{6}(\Lambda=\mathrm{K}, \mathrm{Sn})$ by examining the electronic structure of this compound on the basis of the crystal structure.

\section{Crystallographic Data}

The crystal structures of $\mathrm{KMO}_{4} \mathrm{O}_{6}$, and $\mathrm{SnMo}_{4} \mathrm{O}_{6}$, are almost similar to each other except the difference between the oxidation state and the size of the cation. ${ }^{1.2}$ The perspective view of the structure of $\mathrm{SnMo}_{4} \mathrm{O}_{6}$ along the crystallographic c-direction which is similar to that of $\mathrm{KMO}_{4} \mathrm{O}_{6}$, is shown in Figure 1. It is clcar from the figure that Mo-Mo and Mo-O bonds construct a rectangulas unit. In a reclangular unit, two Mo atoms (Mo-1) on long sides of a

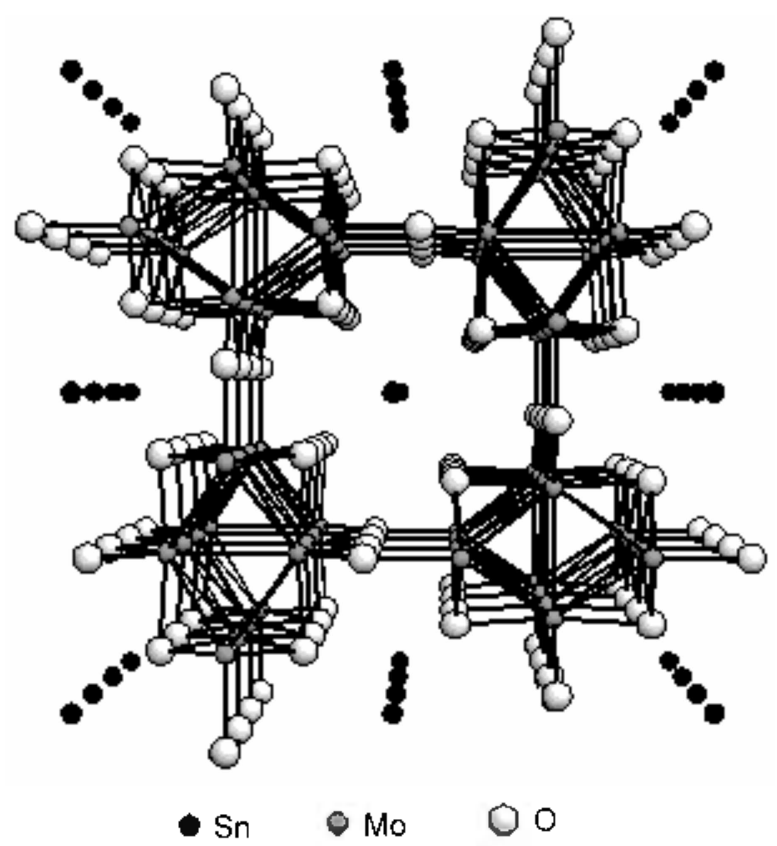

Figure 1. The perspective view of the structure of $\mathrm{SnMo} \mathrm{M}_{4}$. 
Table 1. Crvstal Data and Structure Refinement for $\mathrm{SnMo}_{4} \mathrm{O}_{0}$

\begin{tabular}{ll}
\hline empirical fonmula & $\mathrm{SnMo}_{4} \mathrm{O}_{0}$ \\
fonmula weight & 422.57 \\
temperature, $\mathrm{K}$ & $293(2)$ \\
wavelength, $\AA$ & 0.71073 \\
crystal system & tetragonal \\
space group & $\mathrm{P} 4 / 11 \mathrm{bm}$ \\
& $\mathrm{a}=9.5804(9)$ \\
unit cell dimension, $\AA$ & $\mathrm{b}=9.580 .4(9)$ \\
& $\mathrm{c}=2.8436(4)$ \\
volume, $\AA^{2}$ & $261.00(5)$ \\
$Z$ & 2 \\
density (calculated) & $5.398 \mathrm{mng}^{2} / \mathrm{cm}^{3}$ \\
absorption coefficient & $4.727 \mathrm{~mm}^{-1}$ \\
$\theta$ range for data collection & $3.01^{\circ}-24.85^{\circ}$ \\
\hline
\end{tabular}

Table 2. Crystal Data and Structure Refunement for $\mathrm{KMo}_{4} \mathrm{O}_{5}$

\begin{tabular}{ll}
\hline empirical formula & $\mathrm{KMo}_{+} \mathrm{O}_{6}$ \\
formula weight & 518.86 \\
temperature, $\mathrm{K}$ & 296 \\
wavelength, $A$ & 0.71069 \\
crystal system & tetragonal \\
space group & $\mathrm{P}^{\overline{4}}$ \\
& \\
unit cell dimension, $A$ & $\mathrm{a}=9.636(1)$ \\
& $\mathrm{b}=9.636(1)$ \\
volume, $A^{\text {s }}$ & $\mathrm{c}=2.879(1)$ \\
$Z$ & $267.32(1)$ \\
density (calculated) & 2 \\
$\theta$ range for data collection & $6.44 \mathrm{mg}^{\circ} / \mathrm{cm}^{3}$ \\
\hline
\end{tabular}

rectangle are positioned behind by $\mathrm{c} / 2$ compared with those (Mo-2) on short sides of the rectangle. When the next pair of Mo-2 atoms are added to the four given Mo-Mo cluster in a rectangular unit, then one can easily construct a distorted $\mathrm{Mo}_{6}$ octahedron. which is edge-shared with the next $\mathrm{Mo}_{6}$ along the $\mathrm{c}$-direction. Four rectangular units are bonded through bridging oxygens to construct a channel in which the cations sit. Consequently. the $\mathrm{Mo}_{6}$ octahedra are continuously connected along the c-direction through MoMo bonds. while those are connected along the a- and bdirections through bridging oxygens. Crystallographic data

Table 3. Atomic coordinates $\left(\times 10^{-4}\right)$ and equivalent isotropic displacement parameters $\left(A^{2} \times 10^{-3}\right)$ for $\mathrm{SnMo}_{4} \mathrm{O}_{0}$

\begin{tabular}{lllll}
\hline & $x$ & $y$ & \multicolumn{1}{c}{$z$} & $U(\mathrm{eq})$ \\
\hline $\operatorname{Sn}(1)$ & 0 & 0 & 0 & $9(1)$ \\
$\operatorname{Mo}(1)$ & $3979(1)$ & $1021(1)$ & 0 & $4(1)$ \\
$\operatorname{Mo}(2)$ & $6446(1)$ & $1446(1)$ & -5000 & $9(1)$ \\
$O(1)$ & $2927(5)$ & $2073(5)$ & -5000 & $7(2)$ \\
$O(2)$ & $2359(5)$ & $-412(5)$ & 0 & $10(2)$ \\
\hline
\end{tabular}

$\mathrm{U}(\mathrm{eq})$ is detined as one third of the trace of the orthogonalized $l_{i j}$ tensor.
Table 4 . Atomic coordinates $\left(\times 10^{-4}\right)$ and equivalent isotropic displacement parameters $\left(\AA^{2} \times 10^{-3}\right)$ for $\mathrm{KM}_{4} \mathrm{O}_{\mathrm{i}}$

\begin{tabular}{lllll}
\hline & $\mathrm{x}$ & $\mathrm{y}$ & \multicolumn{1}{c}{$\mathrm{z}$} & $\mathrm{U}(\mathrm{eq})$ \\
\hline $\mathrm{K}(1)$ & 0. & 0. & 0.5 & $1.31(3)$ \\
$\mathrm{K}(2)$ & 0.5 & 0.5 & 0.5 & $1.29(3)$ \\
$\mathrm{Mo}(1)$ & $0.60105(4)$ & $0.10101(4)$ & -0.0002 & $0.347(4)$ \\
$\mathrm{Mo}(2)$ & $0.14276(4)$ & $0.64262(4)$ & $0.5069(3)$ & $0.564(5)$ \\
$\mathrm{O}(1)$ & $0.2052(4)$ & $0.2942(4)$ & $0.494(3)$ & $0.62(4)$ \\
$\mathrm{O}(2)$ & $0.2431(4)$ & $0.0461(4)$ & $-0.001(4)$ & $0.63(4)$ \\
$\mathrm{O}(3)$ & $0.4545(4)$ & $0.2568(4)$ & $-0.010(4)$ & $0.65(4)$ \\
\hline
\end{tabular}

Table 5. Bond lengths $\left[\AA\right.$ ] and angles [deg] for SnMo ${ }_{+} \mathrm{O}_{i}$

\begin{tabular}{|c|c|}
\hline Bond & \\
\hline $\operatorname{Sn}(1)-O(2)$ & $2.294(5)$ \\
\hline $\operatorname{Sin}(1)-\operatorname{Snn}(1)$ & $2.8436(4)$ \\
\hline $\mathrm{Mo}(1)-\mathrm{O}(1)$ & $2.014(5)$ \\
\hline $\mathrm{Mo}(1) \mathrm{O}(2)$ & $2.072(5)$ \\
\hline Mo(l)-Mo(l) & $2.765(2)$ \\
\hline $\operatorname{Mo}(1)-M o(2)$ & $2.7879(8)$ \\
\hline Mo( 1 )-Mo(l $\# 5$ & $2.8436(4)$ \\
\hline $\mathrm{Mo}(2) \mathrm{O}(1) \# 9$ & $2.006(7)$ \\
\hline $\mathrm{Mo}(2)-\mathrm{O}(2) \# 7$ & $2.077(4)$ \\
\hline $\mathrm{Mo}(2)-\mathrm{Mo}(1)$ & $2.7879(8)$ \\
\hline $\mathrm{Mo}(2)-\mathrm{Mo}(1)+3$ & $2.7879(8)$ \\
\hline $\mathrm{Mo}(2)-\mathrm{Mo}(1) 7$ & $2.7879(8)$ \\
\hline $\mathrm{Mo}(2)-\mathrm{Mo}(2)+4$ & $2.8436(4)$ \\
\hline $\mathrm{Mo}(2)-\mathrm{Mo}(2)+3$ & $2.8436(4)$ \\
\hline $\mathrm{O}(2) \# 1-\operatorname{Sn}(1)-\mathrm{O}(2) \# 2$ & 90.0 \\
\hline $\mathrm{O}(2) \# 2-\operatorname{Sin}(1)-\mathrm{O}(2)$ & 180.0 \\
\hline$O(2) \# 1-\operatorname{Sn}(1)-\operatorname{Sn}(1) \# 4$ & 90.0 \\
\hline $\operatorname{Sn}(1) \# 4-\operatorname{Sn}(1)-\operatorname{Sn}(1) \# 5$ & 180.0 \\
\hline $\mathrm{O}(2)-\mathrm{Mo}(1)-\mathrm{Mo}(1) \# 4$ & 90.0 \\
\hline $\mathrm{Mo}(1)+7-\mathrm{Mo}(1)-\mathrm{Mo}(1)+4$ & 90.0 \\
\hline
\end{tabular}

of $\mathrm{KMo}_{4} \mathrm{O}_{6}$ and $\mathrm{SnMo}_{4} \mathrm{O}_{6}$ are given in Table $\mathrm{I}$ and Table 2 , respectively. Cell parameters and fractional coordinates of atoms of $\mathrm{KMO}_{4} \mathrm{O}_{6}$ and $\mathrm{SnMo}_{4} \mathrm{O}_{6}$ for the calculation are given in Table 3 and Table 4, respectively. The cation-oxygen distance is shorter in $\mathrm{SnMO}_{4} \mathrm{O}_{6}$ (i.e.. $\mathrm{Sn}-\mathrm{O} ; 2.294 \AA$ ) than in $\mathrm{KMO}_{4} \mathrm{O}_{6}$ (i.e.. K-O: $2.770 \AA$ ). The Mo-Mo bond distances are also slightly shorter in $\mathrm{SnMO}_{4} \mathrm{O}_{6}$ (i.e. $2.765 \AA$. $2.788 \AA$ and $2.843 \AA$ ) than those in $\mathrm{KMo}_{4} \mathrm{O}_{6}$ (i.e.. $2.754 \AA .2 .774 \AA$. $2.794 \AA$ and $2.879 \AA$ ). which results in the displacements of the bridging oxygen atoms closer toward the central cation. The selected bond distances and angles in both compounds are listed in Tables 5 and 6 , respectively.

Electrical resistivity data. The electrical resistivity data along the crystallographic c-direction of $\mathrm{SnMo}_{4} \mathrm{O}_{6}$ and $\mathrm{KMO}_{4} \mathrm{O}_{6}$ as a function of temperature are shown in Figures 2 and 3, respectively. It is clear from the resistivity data that $\mathrm{SnMO}_{4} \mathrm{O}_{6}$ and $\mathrm{KMO}_{4} \mathrm{O}_{6}$ show metal-insulator transitions at $50 \mathrm{~K}$ and $120 \mathrm{~K}^{2}$ respectively. The difference in the metalinsulator transition temperature in $\mathrm{SnMo}_{4} \mathrm{O}_{6}$ and $\mathrm{KMo}_{4} \mathrm{O}_{6}$ will be analyzed by examining the structural and electronic properties of both compounds. The resistivity along the c- 
Table 6. Se]ceted bond lengths $[\dot{A}]$ for $\mathrm{KMO}_{+} \mathrm{O}_{6}$

\begin{tabular}{|c|c|}
\hline Bond & \\
\hline $\mathrm{K}(1)-\mathrm{O}(2)$ & $2.783(7)[4 \times 1$ \\
\hline $\mathrm{K}(2)-\mathrm{O}(2)$ & $2.787(7)[4 \times 1$ \\
\hline $\mathrm{K}(2)-\mathrm{O}(3)$ & $2.800(7)[4 \times]$ \\
\hline $\mathrm{K}(2)-\mathrm{O}(3)$ & $2.770(7)[4 \times 1$ \\
\hline $\operatorname{Mo}(1)-O(1)$ & $2.013(6)$ \\
\hline $\operatorname{Mo}(1)-O(1)$ & $2.037(6)$ \\
\hline $\mathrm{Mo}(1)-\mathrm{O}(2)$ & $2.066(4)$ \\
\hline $\operatorname{Mo}(1)-O(3)$ & $2.061(4)$ \\
\hline $\operatorname{Mo}(2)-O(1)$ & $2.069(4)$ \\
\hline $\mathrm{Mo}(2)-\mathrm{O}(2)$ & $2.049(9)$ \\
\hline $\mathrm{Mo}(2)-\mathrm{O}(2)$ & $2.027(9)$ \\
\hline $\operatorname{Mo}(2)-O(3)$ & $2.033(9)$ \\
\hline $\operatorname{Mo}(2)-O(3)$ & $2.045(9)$ \\
\hline $\operatorname{Mo}(1)-\operatorname{Mo}(1)$ & $2.879(1) \mid 2 \times 1$ \\
\hline $\operatorname{Mo}(1)-\operatorname{Mo}(1)$ & $2.754(1)$ \\
\hline $\operatorname{Mo}(1)-\operatorname{Mo}(2)$ & $2.794(1) \mid 2 \times 1$ \\
\hline $\operatorname{Mo}(1)-\operatorname{Mo}(2)$ & $2.774(1) \mid 2 \times 1$ \\
\hline $\operatorname{Mo}(1)-\operatorname{Mo}(2)$ & $2.793(1) \mid 2 \times 1$ \\
\hline $\operatorname{Mo}(1)-\operatorname{Mo}(2)$ & $2.773(1) \mid 2 \times 1$ \\
\hline $\operatorname{Mo}(2)-\operatorname{Mo}(2)$ & $2.879(1) \mid 2 \times 1$ \\
\hline
\end{tabular}

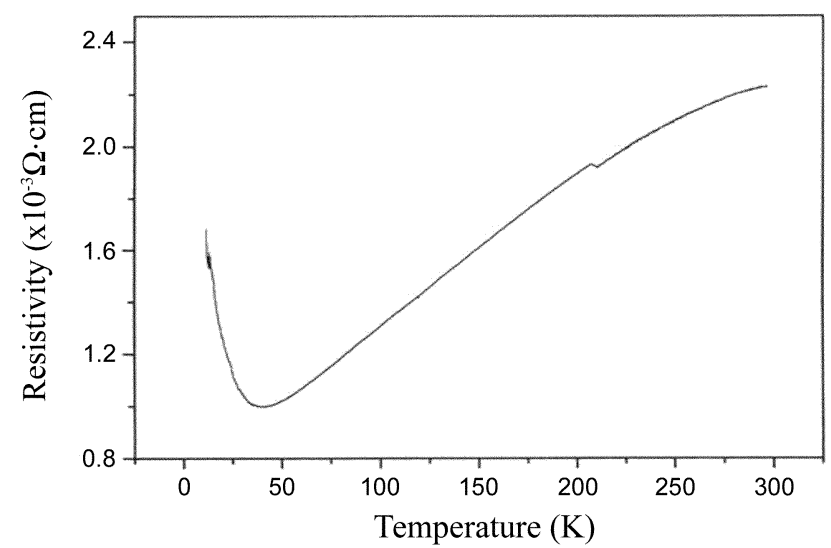

Figure 2. Lilectrical resistivity $(\rho)$ of $\mathrm{SnMO}_{4} \mathrm{O}_{6}$ as a function of temperature (T).

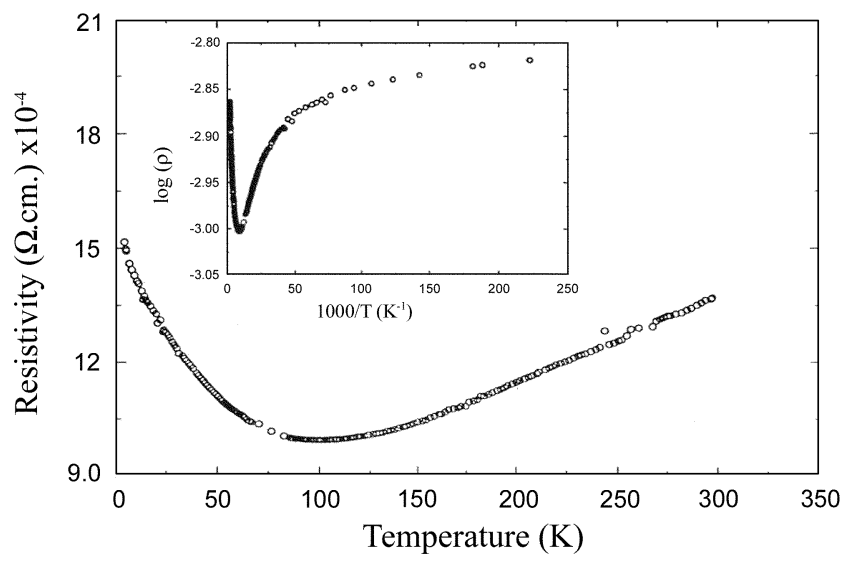

Figure 3. Helectrical resistivity $(\rho)$ of $\mathrm{KMO}_{0} \mathrm{O}_{0}$ as a function ol temperature (1). The inset shows the relationship between $\log (\rho)$ versus $1 / T$.
Table 7. Atomic Parameters used in EHTB Calculations': Valence orbital lonization Potential $\mathrm{H}_{\mathrm{il}}(\mathrm{eV})$ and Exponent of the Slater-lype Orbital $\zeta$

\begin{tabular}{ccccc}
\hline atom & orbital & $\mathrm{H}_{\mathrm{ii}}$ & $\zeta_{1}\left(\mathrm{c}_{1}\right)$ & $\zeta_{2}\left(\mathrm{c}_{2}\right)$ \\
\hline Mo & $4 \mathrm{~d}$ & -10.50 & $4.54(0.5899)$ & $1.90(0.5899)$ \\
& $5 \mathrm{~s}$ & -8.34 & 1.96 & \\
& $5 \mathrm{p}$ & -5.24 & 1.90 & \\
0 & $2 \mathrm{~s}$ & -32.3 & 2.275 & \\
& $2 \mathrm{p}$ & -14.8 & 2.275 & \\
\hline
\end{tabular}

"Parameters are collected from the following data: (a) Clementi, F.: Roetti. C. Aleme Data inclear Data Fables 1974, 14. 177. (b) Mcl cen.

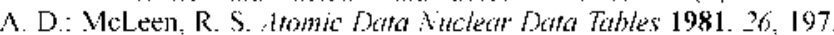
(c) Richardson, J. W.: Blackman, M. J.: Ranochak, J. E. J. (Chem. Phos. 1973. 58,3010 .

axis for $\mathrm{SnMO}_{4} \mathrm{O}_{6}$ and $\mathrm{KMo}_{4} \mathrm{O}_{6}$ at room temperature are about $2.2 \times 10^{-3} \Omega \mathrm{cm}$ and $1.3 \times 10^{-3} \Omega \mathrm{cm}$, respectively.

Electronic structure calculations. The electronic structures of $\mathrm{SnMO}_{4} \mathrm{O}_{6}$ and $\mathrm{KMO}_{4} \mathrm{O}_{6}$ were investigated by performing tight-binding band electronic structure calculations based upon the extended Huckel method. ${ }^{6.7}$ The PC version of CATSAR program was used for the calculations. Atomic parameters adopted in the calculations are shown in Table 7.
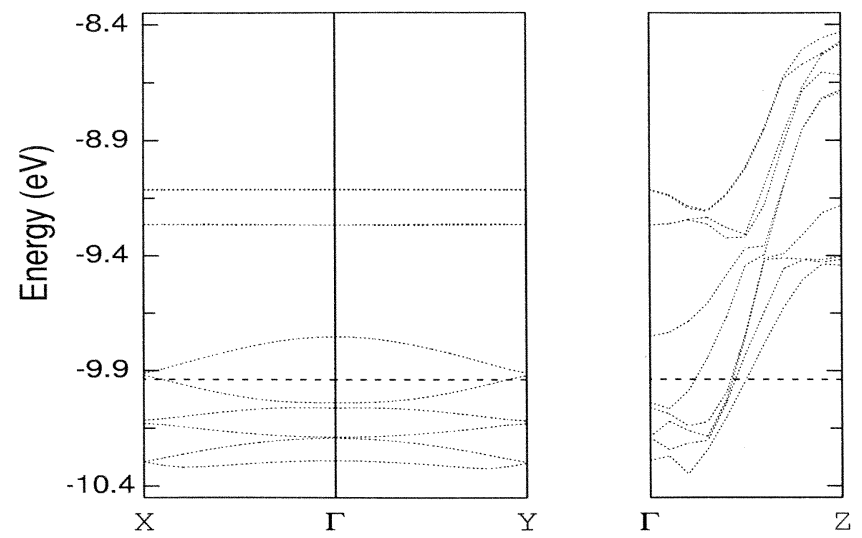

Figure 4. Band dispersions calculated for $\mathrm{SnMo}_{+} \mathrm{O}_{6}$ where $\Gamma$. X. Y. and 7 represent $(0.0 .0)$. $(\pi / \mathrm{a} .0 .0) .(0 . \pi / \mathrm{b}, 0)$ and $(0.0 . \pi / \mathrm{c})$. The dashed lines reler to the l'ermi energy.
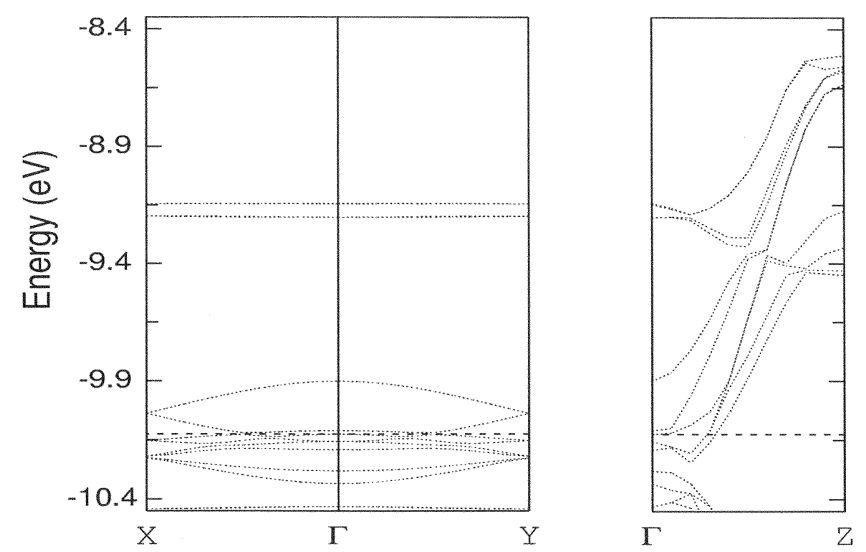

Figure 5. Band dispersions calculated for $\mathrm{KMO}_{4} \mathrm{O}_{6}$. 


\section{Results and Discussion}

In each unit cell, there are two sets of $\mathrm{AMo}_{4} \mathrm{O}_{6}$ since $7=2$. $\left(\mathrm{Mo}_{8} \mathrm{O}_{12}\right)^{\mathrm{n}-}$ are, therefore, chosen as a unit for electronic structure calculations for both compounds. Band dispersions calculated for $\left(\mathrm{Mo}_{8} \mathrm{O}_{12}\right)^{\mathrm{t}-}$ units of $\mathrm{SnMO}_{4} \mathrm{O}_{6}$ and $\mathrm{KMO}_{4} \mathrm{O}_{6}$ are shown in Figure 4 and 5 , respectively, where $\Gamma, X, Y$, and 7. represent $(0,0,0),(\pi / \mathrm{a}, 0,0),(0, \pi \mathrm{b}, 0)$ and $(0,0, \pi / \mathrm{c})$ in the reciprocal lattice, respectively. The dispersion curves along the $\mathrm{a}^{*}$-direction is exactly same to that along the $\mathrm{b}^{*}$-direction in both compounds since the crystals are tetragonal. The bands are strongly dispersive along the $\mathrm{c}^{*}$-direction while those along the $\mathrm{a}^{*}$ - and $\mathrm{b}^{*}$-directions are weakly dispersive. The band dispersions clearly tell us that $\mathrm{SnMo}_{4} \mathrm{O}_{6}$ and $\mathrm{KMO}_{4} \mathrm{O}_{6}$ are said to be a quasi-one-dimensional metal.
Fermi level of $\mathrm{SnMO}_{4} \mathrm{O}_{6}$ is higher than that of $\mathrm{KMO}_{4} \mathrm{O}_{6}$ since Sn contributes more electrons to $\mathrm{Mo}_{4} \mathrm{O}_{6}$ than $\mathrm{K}$. Depending upon the position of Fermi energy, five bands are cut by Fermi energy in $\mathrm{SnMo}_{4} \mathrm{O}_{6}$, while four bands are cut in $\mathrm{KMO}_{4} \mathrm{O}_{6}$.

Fermi surfaces associated with the partially filled band dispersions of $\mathrm{SnMo}_{4} \mathrm{O}_{6}$ and $\mathrm{KMo}_{4} \mathrm{O}_{6}$ are shown in Figures 6 and 7, respectively. In $\mathrm{SnMo}_{4} \mathrm{O}_{6}$, the Fermi surfaces associated with the lowest four bands [see Figures 6(a)-6(d)] are open along the $a^{*}$ - and $b^{*}$-directions while they are closed along the $c^{*}$-direction, which means that the electrical conductivity arises only along the c-axis. On the other hand. the Fermi surface associated with the highest band [see Figure 6(e)] shows 3-dimensional nature, Consequently, electrons moving along the $\mathrm{c}^{*}$-direction dominate to arise the
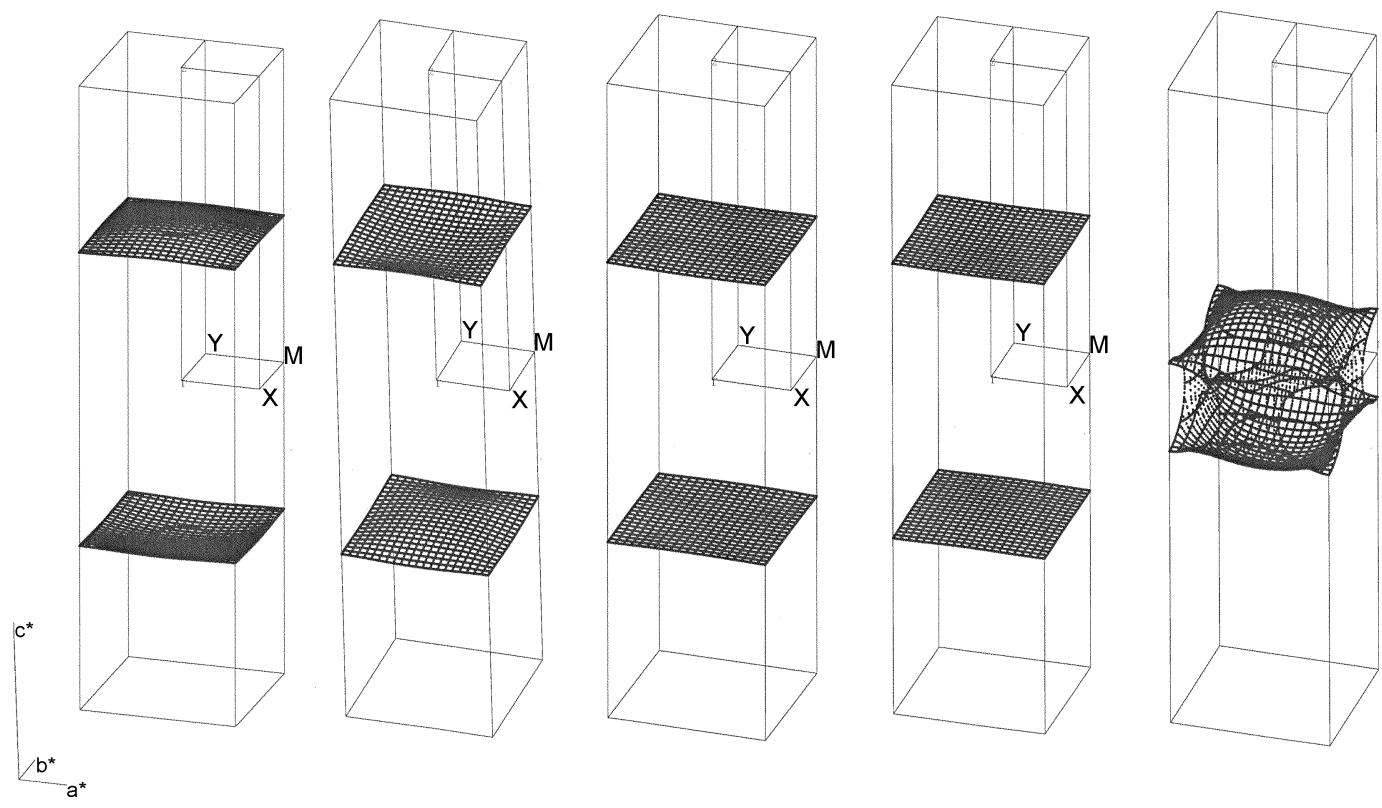

Figure 6. lermi surface associated with the five partially filled hand dispersions of $\mathrm{Sn}_{\mathrm{M}} \mathrm{Mo}_{0} \mathrm{O}_{6}$.
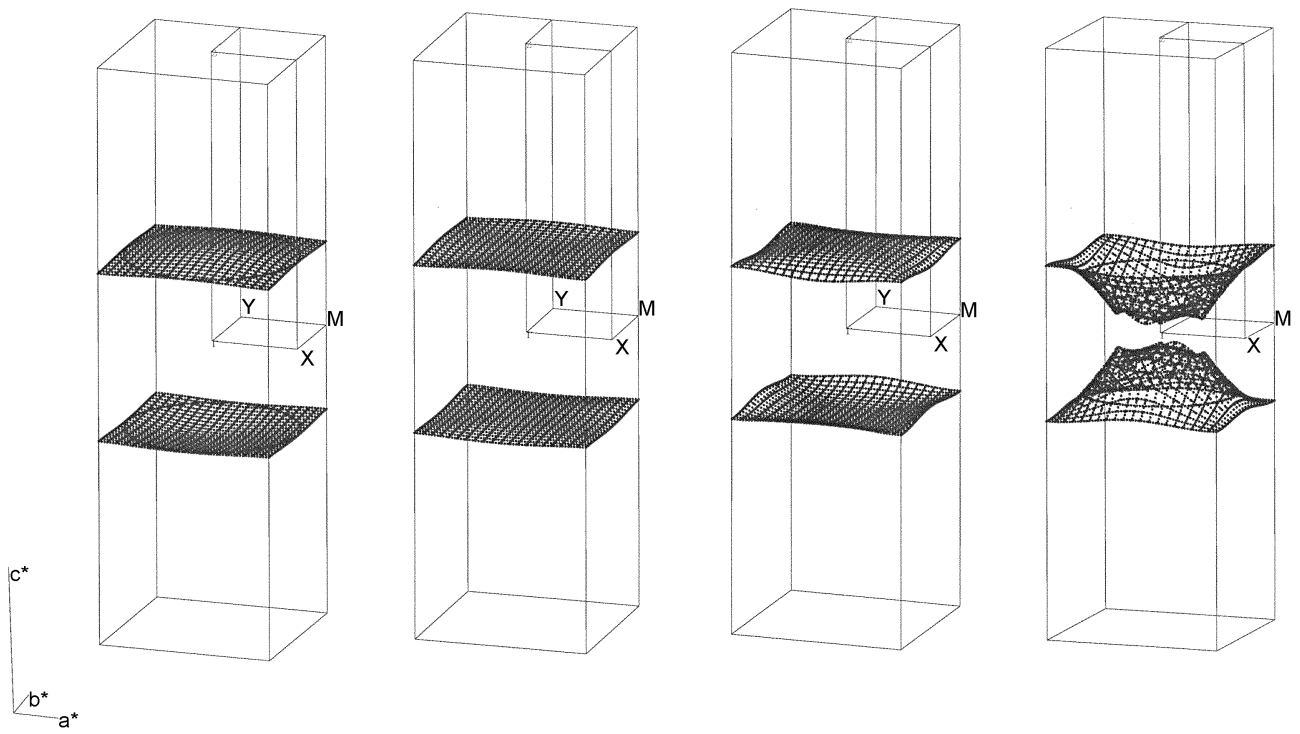

Figure 7. Fermi surfaces associated with the four partially tilled hand dispersions of $\mathrm{KMo}_{4} \mathrm{O}_{6}$. 
metallic property of the compound. Since conductivity of a metal is proportional to the number of electrons per unit volume. that along the $c^{*}$-direction is much higher than those along the other two directions as discussed earlier. and hence $\mathrm{SnMo}_{4} \mathrm{O}_{6}$ possesses $\mathrm{ID}$ character. Similarly to those in $\mathrm{SnMo}_{4} \mathrm{O}_{6}$. the ID Fermi surfaces associated with the lowest two bands of $\mathrm{KMo}_{4} \mathrm{O}_{6}$ are shown in Figures 7(a). 7(b) and $7(\mathrm{c})$, which are open along the $\mathrm{a}^{*}-$ and $\mathrm{b}^{*}$-directions. In addition, the Fermi surface associated with the highest band [see Figure 7(d)] shows 3-dimensional nature. Generally the ID Fermi surface is well nested as one can find in the figures. There are four and three 1D Fermi surfaces in $\mathrm{SnMo}_{4} \mathrm{O}_{6}$ and $\mathrm{KMo}_{4} \mathrm{O}_{6}$, respectively. In addition, the shape of the Fermi surfaces is flatter in those of $\mathrm{SnMo}_{4} \mathrm{O}_{6}$ than in those of $\mathrm{KMo}_{4} \mathrm{O}_{6}$. The nested area is, therefore. larger in $\mathrm{SnMo}_{4} \mathrm{O}_{6}$ than in $\mathrm{KMo}_{4} \mathrm{O}_{6}$. A metallic state may not be stable when its Fermi surface is nested, and is susceptible to become an insulating state when temperature is lovered. The metal-insulator(M-I) transition leads to a charge density wave $(\mathrm{CDW})$ state or a spin density wave (SDW) state. . $^{8-\mathrm{ji}}$ Let us discuss why a Fermi surface nesting is important in introducing an M-I transition by investigating the orbital mixing between an occupied and unoccupied levels. ${ }^{\text {j( }}$ For a ID metal, an occupied wave vector $\mathrm{k}$ and a unoccupied wave vector $k^{\prime}$ form an occupied orbital $\Phi(k)$ and a unoccupied orbital $\Phi(k)$, respectively. An orbital mixing between $\Phi(k)$ and $\Phi\left(k^{\prime}\right)$ produces new orbitals $\Psi(k)$ and $\Psi\left(k^{\prime}\right)$.

$$
\begin{aligned}
& \Psi(k) \propto \Phi(k)+\gamma \Phi\left(k^{\prime}\right) \\
& \Psi\left(k^{\prime}\right) \propto-\gamma \Phi(k)+\Phi\left(k^{\prime}\right)
\end{aligned}
$$

where $\gamma$ is a mixing coeffiecient. The extent of the orbital mixing is determined by the energy difference between the original orbitals $\Phi(k)$ and $\Phi(k)$. At the Fermi level. by definition. two orbitals $\Phi(k)$ and $\Phi\left(k^{\prime}\right)$ are degenerate. Therefore. the orbital mixing between them is significant and so is the interaction energy $\langle\Phi(k)| H \eta \Phi(k\rangle)$. When a Fermi surface is nested by a vector $\mathrm{q}$. the orbital nixing can be performed for all wave vectors in the nested region of the First Brillouin Zone (FBZ), thereby leading to the sets of new orbitals $\{\Phi(k)\}$ and $\{\Phi(k)\}$ differing in their wave vectors by $q=k-k^{\prime}$. As the nesting area is large. therefore. the amount of orbital mixing is large and so is the extent of interaction energy. This large amount of energy becomes the driving force to change the structure which leads to an M-I transition even at low temperature. Consequently: the M-I transition temperature in $\mathrm{SnMo}_{4} \mathrm{O}_{6}$ is lower than that in $\mathrm{KMo}_{+} \mathrm{O}_{6}$. The unnested Fermi surface associated with the highest bands in both compounds may exhibit some metallic character for the compounds even after the M-I transition. But when the change in the crystal structure caused by the M-I transition associated from the nested Fermi surfaces is strong enough. the compound after the M-I transition may' not have partially filled bands.

As the interatomic distance becomes longer. the overlap between atoms would eventually become smaller. and all bands. even the partially filled conduction bands. would become narrower. As the conduction band become narrower. the velocity of the electrons in it would diminish and the conductivity of the metal would drop to zero which means that it becomes an insulator. ${ }^{12}$ In $\mathrm{SnMo}_{4} \mathrm{O}_{6}$ and $\mathrm{KMO}_{4} \mathrm{O}_{6}$, conduction arises along the c-direction where Mo-Mo and Mo-O bonds are constructed. As mentioned in crystallographic data. Mo-Mo and Mo-O distances are shorter in $\mathrm{SnMO}_{4} \mathrm{O}_{6}$ than in $\mathrm{KMo}_{4} \mathrm{O}_{6}$. So the overlap in Mo-Mo and Mo-O bonds is smaller in $\mathrm{KMo}_{4} \mathrm{O}_{6}$ than in $\mathrm{SnMo}_{4} \mathrm{O}_{6}$. In addition, the velocity of electrons is a function of temperature. In the long rum, the metallic property is disappeared even at higher temperature and become an insulator in $\mathrm{KMO}_{4} \mathrm{O}_{6}$. The M-I transition appears. therefore. at higher temperature in $\mathrm{KMo}_{4} \mathrm{O}_{6}$ than in $\mathrm{SnMo}_{4} \mathrm{O}_{6}$ as shown in the resistivity data. Lov-dimensional metals frequently possess electronic instabilities toward an M-I transition or a metalsuperconductor transition. Whatever it shows. a phase transition occurs at certain temperature. It means that the position of the transition temperature $\left(\mathrm{T}_{\mathrm{c}}\right)$ is affected by the similar factors. In the metal-superconducting transition. the

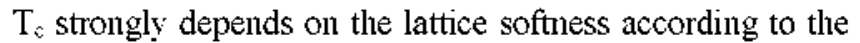
BCS theory. ${ }^{13}$ The compound having softer lattice exhibits higher $\mathrm{T}_{c}$. The lattice of $\mathrm{KMo}_{4} \mathrm{O}_{6}$ is softer than that of $\mathrm{SnMO}_{4} \mathrm{O}_{6}$, as one can find in the bond distances. Thus. the higher $\mathrm{M}-\mathrm{I}$ transition temperature in $\mathrm{KMo}_{4} \mathrm{O}_{6}$ is also reasonable from the view point of lattice softness.

\section{Conclusions}

$\mathrm{KMO}_{4} \mathrm{O}_{6}$ and $\mathrm{SnMo}_{4} \mathrm{O}_{6}$ are quasi-one dimensional metallic compounds at room temperature. Although they are isostructural, $\mathrm{KMO}_{4} \mathrm{O}_{6}$ and $\mathrm{SnMO}_{4} \mathrm{O}_{6}$ show the metal-insulator transition at $120 \mathrm{~K}$ and $50 \mathrm{~K}$, respectively. The investigations on the structural and electronic properties of these compounds tell us that the difference of the M-I transition temperature is strongly governed by the Fermi surface nesting area and the lattice softness. The large area of Fermi surface nesting leads to an M-I transition even at low temperature. Therefore. the higher M-I transition temperature in $\mathrm{KMo}_{4} \mathrm{O}_{6}$ is well understood. In addition. $\mathrm{Mo}-\mathrm{Mo}_{0}$ and $\mathrm{Mo}-\mathrm{O}$ distances are shorter in $\mathrm{SnMo}_{4} \mathrm{O}_{6}$ than in $\mathrm{KMo}_{4} \mathrm{O}_{6}$. So the overlap in Mo-Mo and $\mathrm{Mo}-\mathrm{O}$ bonds is smaller in $\mathrm{KMo}_{4} \mathrm{O}_{6}$. In addition. the velocity of electrons is a function of temperature. Therefore, the metallic property is disappeared even at higher temperature and become an insulator in $\mathrm{KMo}_{4} \mathrm{O}_{6}$. In the long run. the longer $\mathrm{Mo}-\mathrm{O}$ and Mo-Mo bond distances make $\mathrm{KMO}_{4} \mathrm{O}_{6}$ lattice become softer. thereby leading to higher M-I transition temperature. As a result. the Fermi surface nesting area and lattice softness are the governing factors to determine the metal-insulator transition temperature in $\mathrm{AMO}_{4} \mathrm{O}_{6}$ compounds.

Acknowledgement. This work was financially supported by Wonkwang university in the program year of 2003.

\section{References}

1. Ramanujachary. K. V: Greenblatt. M.: Jones. E. B.: McCarroll. 
W. H. J. Solid State (Chem. 1993.102.69

2. Jung. D.: Lee. B.-H.: Kim. S.-J.: Kang. W. Chem. Mater 2001.13. 1625 .

3. (a). Greenblatt. M:- Vincent. H: Marezio. M. Low-Dimensional Properties of A follbdentm Bronzes and Oxides: Schlenker. C.. Ed.: Kluwer publisher: 1989. (b) Kang. D.-B. Bull. Korean Chem. Soc. 1995. 16.929.

4. Whangbo. M.-H.: Canadell. E. Acc. Chem. Res. 1989.22. 375

5. Wilson, J. A.: DiSalvo. F. J.: Malajan, S. Adh Phos. 1975, 2f, 117

6. Ammeter I. H: Bürgi, H.-B.: Thibeault. J.: Hoffmann, R. $J$. Am.
Chen. Soc. 1978. 100. 3686 .

7. Whangbo. M.-H.: Hoftimann. R. J. Am. Chem. Soc.. 1978. 100. 6093 .

8. Whangbo. M.-H. J. Chent. Phes. 1979, 70, 4963

9. Whangbo. M.-H. J. Chent. Phis $1980,73,3854$

10. Whangbo. M.-H. d. Chem. Phus. 1981. 75.4983

11. Whangbo. M.-H. Acc. Chem. Res. 1983. 16. 95.

12. Asheroft. N. W. Mermit1. N. D. Solid State Plysics: Saunders College Publisher: Philadelphia. 1975: p 685.

13. MoMillan. W. L. Phys. Rev. 1968. 167, 331. 